\title{
Pengaruh teknik efflurage dan petrissage terhadap penurunan perasaan lelah pasca latihan pencak silat
}

\author{
Jeane Betty Kurnia Jusuf ${ }^{1 *}$, Andri Tria Raharja ${ }^{1}$, Nanda Alfian Mahardhika ${ }^{1}$, \\ Rifqi Festiawan ${ }^{2}$ \\ ${ }^{1}$ Program Studi Pendidikan Olahraga, Fakultas Keguruan dan Ilmu Pendidikan, Universitas \\ Muhammadiyah Kalimantan Timur. Jalan Ir. H. Juanda No 15 Samarinda, Indonesia \\ ${ }^{2}$ Universitas Jenderal Soedirman. Jalan Profesor DR. HR Boenyamin No.708, Banyumas, Jawa \\ Tengah, 53122, Indonesia. \\ * Corresponding Author. Email: jbk567@umkt.ac.id
}

Received: 9 March 2020; Revised: 31 March 2020; Accepted: 21 April 2020

\begin{abstract}
Abstrak: Tujuan dari penelitian ini difokuskan pada pengkajian berikut: (1) untuk menurunkan perasaan lelah pasca latihan mahasiswa Unit Kegiatan Mahasiswa (UKM) pencak silat Tapak Suci di Universitas Muhammadiyah Kalimantan Timur (UMKT), (2) melakukan analisis dan uji coba teknik efflurage dan pettrisage terhadap penurunan perasaan lelah. Jenis pendekatan penelitian ini merupakan jenis pendekatan deskriptif kuantitatif. Subjek penelitian ini adalah mahasiswa yang aktif di UKM Tapak Suci di Universitas Muhammadiyah Kalimantan Timur. Analisis data yang digunakan dalam penelitian ini menggunakan teknik analisis deskriptif kuantitatif. Setelah data terkumpul, data dianalisis menggunakan analisis regresi. Hasil data yang diperoleh ada pengaruh teknik efflurage terhadap perasaan lelah pada UKM Pencak Silat Tapak Suci di UMKT. Hasil data ini membuktikan bahwa pengaruh teknik efflurage dan teknik petrissage terhadap penurunan perasaan lelah pasca latihan pada UKM Pencak Silat Tapak Suci di UMKT.
\end{abstract}

Kata Kunci: efflurage, petrissage, sport massage, penurunan perasaan lelah

\section{Effect of efflurage and petrissage techniques on feeling decreased tired after training of pencak silat}

\begin{abstract}
The purpose of this study is focused on the following assessment: (1) to reduce feelings of fatigue after the exercise of Tapak Suci martial arts organization students at Universitas Muhammadiyah Kalimantan Timur (UMKT), (2) to analyze and test efflurage and pettrisage techniques for reducing fatigue. This type of research approach is a type of quantitative descriptive approach. The subjects of this study were students who were active in UKM Tapak Suci at Muhammadiyah University of East Kalimantan. Analysis of the data used in this study uses quantitative descriptive analysis techniques. After the data is collected, the data is analyzed using regression analysis. The results of the data obtained that there is an effect of efflurage techniques on fatigue in UKM Tapak Suci Silat in UMKT. The results of this data prove that the effect of efflurage techniques and petrissage techniques on the reduction of post-training fatigue feelings in Pencak Silat Tapak Suci UKM at UMKT.
\end{abstract}

Keywords: efflurage, petrissage, sports massage, decreased feeling of fatigue

How to Cite: Jusuf, J., Raharja, A., Mahardhika, N., \& Festiawan, R. (2020). Pengaruh teknik effleurage dan petrissage terhadap penurunan perasaan lelah pasca latihan Pencak Silat. Jurnal Keolahragaan, 8(1), 1-8. doi:https://doi.org/10.21831/jk.v8i1.30572

\section{PENDAHULUAN}

Kemajuan dan perkembangan olahraga saat ini sangat membudaya di seluruh dunia baik di Indonesia maupun internasional. Pelaku dalam kegiatan olahraga sangat beragam mulai dari wanita, pria, anak-anak, dewasa bahkan orang tua. Kegiatan olahraga yang dilakukan memiliki tujuan masingmasing misalnya untuk meningkatkan prestasi, meningkatkan kesehatan dan meningkatkan kebugaran tubuh. Sehingga olahraga dirasa menjadi suatu kebutuhan yang tidak akan dipisahkan dalam kehidupan. 
Jurnal Keolahragaan 8 (1), 2020 - 2

Jeane Betty Kurnia Jusuf, Andri Tria Raharja, Nanda Alfian Mahardhika, Rifqi Festiawan

Salah satu kegiatan olahraga yang memiliki tujuan ke arah prestasi, kesehatan dan kebugaran adalah pencak silat.

Pencak silat merupakan salah satu olahraga beladiri dan merupakan budaya asli Indonesia. Pencak silat adalah warisan nenek moyang bangsa Indonesia. Lubis (2004) mengatakan pencak silat adalah olahraga yang terdiri atas sikap (posisi) dan gerak-gerik (pergerakan). Gerakan dasar pencak silat adalah suatu gerakan terencana, terarah, terkoordinasi dan terkendali (Kuswanto, 2016; Saputro et al., 2018). Dalam pertandingan pencak silat teknik-teknik dasar tidak semua digunakan dan dimainkan sesuai dengan ketentuan yang berlaku dan kategori yang dipertandingkan. Kategori tersebut adalah kategori tanding, tunggal, ganda dan regu. Perkembangan bela diri pencak silat di Indonesia sudah sangat berkembang pesat, penyebaran pencak silat sudah mencakup seluruh daerah. Sedangkan di luar negeri sendiri perkembangan pencak silat sudah tersebar baik di Eropa, Asia, Amerika maupun Australia.

Latihan merupakan suatu proses untuk meningkatkan kemampuan penampilan fisik seseorang. Pada waktu pelaksanaan latihan, seorang atlet berlatih secara maksimal dalam waktu tertentu, tanpa disadari hal ini menyebabkan otot-otot mengalami kelelahan. Kelelahan pada jaringan otot dan darah akan menyebabkan terjadinya penimbunan asam laktat. Kelelahan otot ini akan mengakibatkan menurunnya kualitas gerak atlet. Salah satu tanda dari kelelahan otot adalah terjadinya kejang otot (kram), yang disebabkan oleh tidak lancarnya proses resintesis asam laktat menjadi ATP kembali di dalam otot (Sukadiyanto \& Muluk, 2011).

Akibat Intensitas latihan yang padat dan intens, banyak pemain yang mengalami kelelahan sehingga pada saat menjalani program latihan, banyak pemain yang tidak dapat melakukan program secara mksimal. Setiap aktivitas fisik (jasmani) dalam latihan olahraga selalu menyebabkan terjadinya perubahan, antara lain keadaan anatomi, fisiologi, biokimia, dan psikologis pelakunya (Sukadiyanto \& Muluk, 2011). Latihan yang dilakukan dengan intensitas tinggi juga dapat menyebabkan kondisi umum yang merugikan, sehingga banyak atlet yang mengalami overtraining, overuse, dan burnout.

Fisik, teknik, taktik, strategi dan mental merupakan komponen yang tidak bisa lepas dari pencak silat tersebut. Kejuaraan pencak silat nomor tarung mempertemukan dua orang. Jika menang akan bertanding kebabak berikutnya dalam hari tersebut. Maka fisik sangat ditentukan pada pertandingan berikutnya. Recovery atau pemulihan harus sesegera mungkin dilakukan agar fisik tetap terjaga tanpa adanya kelelahan. Berbagai bentuk aktivitas fisik yang dilakukan dengan intensitas tinggi dapat menyebabkan peningkatan kadar asam laktat dalam otot maupun dalam darah. Pada aktivitas submaksimal, sistem yang berperan menyediakan energi $70 \%$ berasal dari sistem glikolisis anaerobik dan 30\% dari sistem aerobik (Bompa \& Haff, 2009; Kusumawardhana, 2016). Aktivitas anaerobik yang berlangsung secara glikolisis anaerobik akan meningkatkan konsentrasi asam laktat dalam otot (Kusumawardhana, 2016).

Berdasarkan penelitian yang dilakukan Purnomo (2011) terjadi peningkatan kadar asam laktat di dalam darah 5 menit setelah latihan maksimal. Akumulasi asam laktat dapat menimbulkan nyeri otot yang dirasakan ketika seserong melakukan aktivitas intensif (Sherwood, 2015). Dari hasil pengamatan lapangan terhadap kondisi pemain yang mengalami kelelahan, pengenalan recovery dengan melakukan observasi pemberian manipulasi masase dilakukan untuk mengetahui manfaat dari manipulasi masase terhadap proses pemulihan tubuh terhadap kelelahan.

Massage berasal dari kata Arab "mash" yang berarti menekan dengan lembut atau kata Yunani "massien" yang berarti "memijat atau melulut" (Priyonoadi, 2008; Purnama \& Graha, 2019). Selanjutnya massage disebut pula sebagai ilmu pijat atau ilmu lulut. Pelaku dalam massage disebut sebagai masseur untuk laki-laki dan masseus untuk wanita. Massage merupakan manipulasi dari struktur jaringan lunak yang dapat menenangkan serta mengurangi stres psikologis dengan meningkatkan hormon morphin endogen seperti endorphin, enkefalin dan dinorfin sekaligus menurunkan stres hormon seperti hormon cortisol, norepinephrine dan dopamine (Best et al., 2008).

Tujuan massage secara umum adalah (1) memperlancar peredaran darah, (2) merangsang sistem syaraf, (3) meningkatkan ketegangan otot dan kekenyalan otot untuk meningkatkan daya kerjanya, (4) membersihkan dan menghaluskan kulit, (5) mengurangi dan menghilangkan ketegangan syaraf dan mengurangi rasa sakit hingga dapat menidurkan pasien (Graha \& Priyonoadi, 2009; Priyonoadi, 2008).

Massage dapat dikelompokkan menjadi beberapa macam, salah satunya adalah sport massage. Sport massage merupakan massage yang khusus digunakan kepada orang yang sehat kondisi badannya, terutama olahragawan (Priyonoadi, 2008). Dari bermacam-macam massage yang ada terdapat dua macam massage yang mempunyai tujuan pemijatan yang sama, yaitu sport massage dan swedish 
massage. Sports massage (masase olahraga) merupakan salah satu modalitas terapi fisik yang digunakan oleh atlet untuk meningkatkan performa fisik, mencegah dan mengatasi cedera serta gangguan fisik lainnya akibat kerja fisik dengan intensitas tinggi (Arovah, 2010). Robertson et al. (2004) menyatakan bahwa sports massage banyak digunakan sebagai modalitas terapi fisik untuk pemulihan dari kelelahan dan cedera otot pada atlet. Secara fisiologis, sports massage terbukti dapat menurunkan denyut jantung, meningkatkan tekanan darah, meningkatkan sirkulasi darah dan limfe, mengurangi ketegangan otot, meningkatkan jangkauan gerak sendi dan mengurangi nyeri (Callaghan, 1993) serta menurunkan kadar enzim creatine kinase dalam darah (Smith et al., 1994; Yudiansyah, 2015).

Dalam sport massage teknik manipulasi yang digunakan adalah effleurage (menggosok), petrissage (comot-tekan), shaking (menggoncang), tapotement (memukul), friction (menggerus) dan masih banyak lagi jenis lainnya. Teknik efflurage adalah gerakan urut mengusap secara ritmis dan dilakukan secara berturut-turut dari bawah ke atas. Efflurage dilakukan menggunakan telapak tangan dan jari yang merapat. Gerakan tangan bergerak meluncur di atas mengalir tanpa terputus, tekanan yang diberikan ringan, dan tekanan yang lebih kuat saat mengarah ke jantung (Ananto, 2017).

Teknik petrissage adalah gerakan memijat masa otot yang dilakukan dengan satu tangan atau kedua tangan. Petrissage dapat melemaskan kekakuan di dalam jaringan. Pelaksanaan gerakan petrissage dilakukan untuk lokasi-lokasi yang lebar sehingga dapat dilakukan dengan kedua tangan menekan secara bersama-sama atau bergantian secara berurutan. Tujuan teknik petrissage adalah melancarkan penyaluran zat-zat pada jaringan di dalam pembuluh darah dan getah bening, seolah-olah diremas dan didorong ke dalam sistem pembuluh tersebut (Goats, 1994).

Tubuh dengan waktu relatif lama tidak mampu melakukan latihan atau aktivitas olahraga yang berat secara terus menerus dan pada tingkat tertentu otot-otot tubuh tidak lagi mampu untuk berkontraksi disebut kelelahan. Kelelahan diartikan sebagai kondisi menurunnya kapasitas ATP yang dikeluarkan secara berlebihan dan disebabkan karena aktivitas yang dilakukan (Giriwijoyo \& Sidik, 2012). Kelelahan pada aktivitas olahraga dapat dicegah atau ditunda dengan cara yang tepat. Salah satu perawatan yang sering dilakukan oleh atlet untuk mengurangi ketegangan otot akibat latihan dan bertanding adalah sport massage.

Untuk mendukung penelitian ini, ada beberapa penelitian yang telah dilakukan terlebih dahulu mengenai sport massage. Penelitian yang dilakukan oleh Ekowati et al. (2012), didapatkan bahwa teknik effleurage mengurangi nyeri dismenorea dengan menstimulus serabut taktil di kulit pada abdomen yang memberikan efek relaksasi pada otot abdomen sehingga spasme otot abdomen berkurang dan dapat memberikan efek distraksi.

Penelitian yang dilakukan oleh Handayani et al. (2013), didapatkan hasil bahwa teknik effleurage dapat menstimulus serabut taktil sehingga sinyal nyeri dapat dihambat. Penelitian yang dilakukan oleh Purwanti (2013) tentang analisis perbedaan terapi disminore dengan metode effleurage, kneading, dan yoga dalam mengatasi disminore didapatkan analisis dengan uji paired $t$-test menunjukkan nilai $p$ value 0.000 artinya adanya berbedaan signifikan skala nyeri sebelum dilakukan terapi dengan pemijatan teknik effleurage. Hasil perhitungan efek size $\mathrm{r} 2=0,875$ yang berarti mempunyai efek besar.

Setiap teknik dalam sport massage memiliki tujuan masing-masing, sehingga dapat meningkatkan kesehatan tubuh secara jasmani dan rohani. Teknik efflurage memiliki tujuan menstimulus serabut taktil, nyeri, terapi disminore yang telah dilakukan sebelumnya. Selain itu, data yang diperoleh peneliti berdasarkan hasil observasi, diperoleh beberapa permasalahan terkait dengan penelitian yaitu: (1) mahasiswa UKM pencak silat tapak suci mengalami perasaan lelah yang sangat tinggi setelah latihan, (2) kualitas gerak mahasiswa UKM pencak silat tapak suci mengalami penurunan, (3) fokus latihan mahasiswa UKM pencak silat tapak suci mengalami penurunan.

Tujuan dari penelitian ini difokuskan pada pengkajian berikut: (1) untuk menurunkan perasaan lelah pasca latihan mahasiswa UKM pencak silat Tapak Suci di UMKT, (2) melakukan analisis dan uji coba teknik efflurage dan pettrisage terhadap penurunan perasaan lelah. Urgensi penelitian ini adalah (1) Penanganan perasaan lelah pada mahasiswa UKM pencak silat, (2) teknik efflurage dan pettrisage dapat menurunkan perasaan lelah. Berdasarkan penjelasan yang telah dikemukakan tersebut membuat peneliti tertarik untuk melakukan penelitian tentang pengaruh teknik efflurage dan petrissage terhadap perasaan lelah pasca latihan mahasiswa UKM Pencak Silat Tapak Suci di Universitas Muhammadiyah Kalimantan Timur (UMKT). 


\section{METODE}

Jenis pendekatan penelitian ini merupakan jenis pendekatan deskriptif kuantitatif. Penelitian ini adalah penelitian deskriptif artinya metode yang digunakan adalah survai, dengan teknik pengumpulan data berupa angket (kuisioner). Menurut Sugiyono (2010), penelitian deskriptif digunakan untuk mendeskripsikan atau menggambarkan data yang telah terkumpul sebagaimana adanya.

Permasalahan yang akan diangkat tentang pengaruh teknik efflurage dan petrissage terhadap penurunan perasaan lelah pasca latihan mahasiswa UKM pencak silat tapak suci di UMKT dengan mencari informasi penting dan data lalu dianalisis dengan menggunakan statistik deskriptif. Adapun jenis data yang dikumpulkan dalam penelitian ini adalah data primer. Data primer adalah materi informasi yang diperoleh dari penelitian langsung dari tempat yang menjadi objek berupa data yang belum diolah yang diperoleh dari responden.

\section{Waktu dan Tempat Penelitian}

Penelitian ini dilaksanakan di Universitas Muhammadiyah Kalimantan Timur. Pengambilan data dilaksanakan pada bulan Mei 2018 sampai dengan Juli 2018.

\section{Subjek Penelitian}

Subjek penelitian ini adalah mahasiswa yang aktif tergabung pada UKM Tapak Suci di Universitas Muhammadiyah Kalimantan Timur. Teknik sampling yang digunakan pada penelitian ini adalah teknik sampling purposive atau penentuan sampel dengan pertimbangan tertentu (Sugiyono, 2010) dengan jumlah 10 responden yang sedang mengikuti persiapan Pekan Olahraga Mahasiswa Nasional (POMNAS) tahun 2019.

\section{Instrumen Penelitian}

Dalam penelitian ini, peneliti membuat kisi-kisi berdasarkan teori yang telah disampaikan mengenai perasaan lelah. Adapun kisi-kisi kuesioner dapat dilihat pada Tabel 1.

Tabel 1. Kuesioner Penelitian

\begin{tabular}{cl}
\hline No. & \\
\hline 1. & Massage pada bagian tungkai atas (paha) bagian belakang dan samping \\
& a. Manipulasi Effleurage I,II dan III \\
b. Manipulasi petrissage & Massage pada daerah tungkai bawah bagian belakang \\
2. Manipulasi Effleurage I dan II \\
b. Manipulasi Petrissage I dan II \\
Massage pada daerah tumit dan tapak kaki \\
a. Manipulasi Effleurage I dan II \\
b. Manipulasi Petrissage \\
Massage pada daerah tengkuk and bahu \\
a. Manipulasi Effleurage I dan II \\
b. Manipulasi Petrissage
\end{tabular}

Guna menguji ketepatan instrumen pengumpul data, sebelum penelitian dimulai juga dilakukan uji validitas dan reliabilitas kuesioner. Uji validitas dilakukan untuk mengetahui kemampuan kuesioner dalam mengukur variabel. Validitas kuesioner pada penelitian ini diuji melalui dua tahap. Pada tahap pertama, peneliti melakukan validitas isi kuesioner (content validity). Validitas isi dilakukan untuk mengetahui sejauh mana kuesioner tersebut mewakili semua aspek yang dianggap sebagai kerangka konsep. Validasi isi dalam penelitian ini dilakukan pada 3 orang ahli dengan hasil judgment dari ahli berupa masukan yang kemudian dijadikan rekomendasi untuk perbaikan isi dalam kuesioner tersebut. Tahap kedua yaitu melakukan uji coba kuesioner kepada kelompok yang mempunyai karakteristik sama seperti subjek penelitian. Uji coba kuesioner dilakukan kepada 20 orang mahasiswa yang merupakan anggota Unit Kegiatan Mahasiswa (UKM) pencak silat. Setelah dianalisis dengan metode Corrected Item Total Correlation, yaitu mengkorelasikan skor item pertanyaan dengan skor total pertanyaan dan mengkorelasikannya terhadap nilai koefisien tersebut. Selain itu, uji reliabilitas dengan metode AlphaCronbach memperoleh nilai alpha sebesar $0,854(>0,70)$ sehingga kuesioner dinyatakan reliabel dan layak untuk digunakan sebagai instrumen penelitian 


\section{Teknik Pengumpulan Data}

Menurut Arikunto (2010), instrumen adalah alat pada waktu peneliti menggunakan sesuatu metode. Menurut Arikunto (2010), Instrumen pengumpulan data adalah alat bantu yang dipilih dan digunakan oleh peneliti dalam kegiatannya mengumpulkan agar kegiatan tersebut menjadi sistematis dan dipermudah olehnya.

Jenis data dari penelitian ini adalah data kualitatif dan kuantitatif. Teknik pengumpulan data kualitatif diambil dengan menggunakan teknik angket. Sedangkan teknik pengumpulan data kuantitatif diambil dengan menganalisis skor-skor pada lembar pertanyaan pada kuesioner. Pertanyaan dalam kuesioner berupa pernyataan-pernyataan yang berpedoman pada indikator-indikator variabel. Untuk memudahkan responden menjawab pertanyaan atau pernyataan maka penelitian ini menggunakan skala likert.

Penskoran digunakan dengan menggunakan skala Likert. Menurut Hadi (1991), skala Likert merupakan skala yang berisi lima tingkat jawaban mengenai kesetujuan responden terhadap statemen atau pernyataan yang dikemukakan mendahului opsi jawaban yang disediakan Untuk memberikan skor dari setiap pernyataan yang dijawab oleh responden yang positif diberikan skor: SN (Sangat Nyaman) $=5, \mathrm{~N}($ Nyaman $)=4, \mathrm{~N}($ Normal $)=3, \mathrm{TN}($ Tidak Nyaman $)=2$, dan STN $($ Sangat Tidak Nyaman $)=1$.

\section{Teknik Analisis Data}

Analisis data yang digunakan dalam penelitian ini menggunakan teknik analisis deskriptif kuantitatif. Data yang diperoleh adalah data kuantitatif yang berupa pilihan dengan 5 alternatif jawaban. Setelah data terkumpul, data dianalisis menggunakan analisis regresi. "Persamaan regresi dapat digunakan untuk melakukan prediksi seberapa tinggi nilai variabel dependen bila nilai variabel independen dimanipulasi (diubah-ubah) (Sugiyono, 2010). Analisis ini dilakukan untuk membuktikan hipotesis yang diajukan, apakah masing-masing variabel dependen berpengaruh terhadap variabel dependen.

\section{HASIL DAN PEMBAHASAN}

\section{Hasil}

Berdasarkan data hasil penelitian yang telah dikumpulkan oleh peneliti dari UKM Pencak Silat Tapak Suci di UMKT, kemudian akan dilakukan analisis data. Analisis data diperoleh dengan memasukkan data ke dalam perhitungan regresi berganda pada Tabel 2.

Tabel 2. Perhitungan Regresi Linier Berganda antara Efflurage (X1), Petrissage (X2), dengan Perasaan Lelah (Y) Pada UKM Pencak Silat Tapak Suci di UMKT

\begin{tabular}{ccccccccc}
\hline $\mathrm{X}_{1}$ & $\mathrm{X}_{2}$ & $\mathrm{Y}$ & $\mathrm{X}_{1}{ }^{2}$ & $\mathrm{X}_{2}{ }^{2}$ & $\mathrm{Y}^{2}$ & $\mathrm{X}_{1} \mathrm{X}_{2}$ & $\mathrm{X}_{1} \mathrm{Y}$ & $\mathrm{X}_{2} \mathrm{Y}$ \\
\hline 20 & 20 & 20 & 400 & 400 & 400 & 400 & 400 & 400 \\
17 & 20 & 17 & 289 & 400 & 289 & 340 & 289 & 340 \\
16 & 12 & 17 & 256 & 144 & 289 & 192 & 272 & 204 \\
17 & 18 & 19 & 289 & 324 & 361 & 306 & 323 & 342 \\
20 & 20 & 20 & 400 & 400 & 400 & 400 & 400 & 400 \\
16 & 16 & 16 & 256 & 256 & 256 & 256 & 256 & 256 \\
17 & 15 & 16 & 289 & 225 & 256 & 255 & 272 & 240 \\
16 & 16 & 17 & 256 & 256 & 289 & 256 & 272 & 272 \\
17 & 17 & 17 & 289 & 289 & 289 & 289 & 289 & 289 \\
17 & 17 & 17 & 289 & 289 & 289 & 289 & 289 & 289 \\
173 & 171 & 176 & 3013 & 2983 & 3118 & 2983 & 3062 & 3032 \\
\hline
\end{tabular}

Tabel 3. Tabel Variable Penelitian

\begin{tabular}{lccc}
\hline \multicolumn{4}{c}{ Variables Entered/Removed $^{\mathrm{a}}$} \\
\hline & Variables Entered & Variables Removed & Method \\
\hline 1 & $\mathrm{X} 2, \mathrm{X} 1^{\mathrm{b}}$ & & .Enter \\
\hline
\end{tabular}

a. Dependent Variable: Y

b. All requested variables entered. 
Jurnal Keolahragaan 8 (1), 2020 - 6

Jeane Betty Kurnia Jusuf, Andri Tria Raharja, Nanda Alfian Mahardhika, Rifqi Festiawan

Tabel 4. Tabel Ringkasan model (Model Summary)

\begin{tabular}{|c|c|c|c|c|}
\hline \multicolumn{5}{|c|}{ Model Summary } \\
\hline Model & $\mathrm{R}$ & R Square & Adjusted R Square & Std. Error of the Estimate \\
\hline 1 & $.851^{\mathrm{a}}$ & .724 & .645 & .89647 \\
\hline
\end{tabular}

a. Predictors: (Constant), X2, X1

Tabel 5. Tabel ANOVA

\begin{tabular}{llrrrrr}
\hline \multicolumn{7}{c}{ ANOVA $^{\mathrm{a}}$} \\
\hline Model & Sum of Squares & df & Mean Square & F & Sig. \\
\hline 1 & Regression & 14.774 & 2 & 7.387 & 9.192 & $.011^{\text {b }}$ \\
& Residual & 5.626 & 7 & .804 & & \\
& & 20.400 & 9 & & & \\
\hline
\end{tabular}

a. Dependent Variable: Y

b. Predictors: (Constant), X2, X1

Tabel 6. Tabel Koefisien

\begin{tabular}{|c|c|c|c|c|c|}
\hline \multicolumn{6}{|c|}{ Coefficients $^{\mathrm{a}}$} \\
\hline \multirow[b]{2}{*}{ Model } & \multicolumn{2}{|c|}{ Unstandardized Coefficients } & Standardized Coefficients & \multirow[b]{2}{*}{$\mathrm{t}$} & \multirow[b]{2}{*}{ Sig. } \\
\hline & $\mathrm{B}$ & Std. Error & Beta & & \\
\hline 1 (Constant) & 2.980 & 3.540 & & .842 & .428 \\
\hline $\mathrm{X} 1$ & .801 & .287 & .79 & 2.790 & .027 \\
\hline $\mathrm{X} 2$ & .044 & .168 & .07 & .264 & .800 \\
\hline
\end{tabular}

a. Dependent Variable: Y

Hasil analisis data dengan menggunakan rumus regresi sederhana yang menggunakan rumus $\mathrm{Y}=$ $\mathrm{a}+\mathrm{bX}_{2}$ Pada tingkat signifikansi dari korelasi digunakan rumus $\mathrm{F}_{\text {Hitung }}$ bahwa $\mathrm{F}_{\text {hitung }} 9.192>0.724 \mathrm{~F}_{\text {tabel }}$, ini berarti ada pengaruh teknik petrissage $(\mathrm{X} 2)$ terhadap penurunan perasaan lelah (Y) pada mahasiswa UKM Pencak Silat Tapak Suci di UMKT. Hal ini menjelaskan bahwa pemberian teknik petrissage pada: (1) bagian tungkai atas (paha) bagian belakang dan samping; (2) daerah tungkai bawah bagian belakang; (3) daerah tumit dan tapak kaki; (4) daerah tengkuk dan bahu memilik pengaruh yang besar terhadap penurunan perasaan lelah pasca latihan pada mahasiswa UKM Pencak Silat Tapak Suci di UMKT. Dengan pemberian teknik petrissage yang baik kepada mahasiswa UKM Tapak Suci di UMKT, maka hasil penurunan perasaan lelah pada UKM Tapak Suci di UMKT dapat menurunkan secara signifikan.

\section{Pembahasan}

Hasil analisis terhadap Efflurage, Petrissage, dengan Perasaan Lelah menjelaskan bahwa pemberian teknik efflurage pada: (1) bagian tungkai atas (paha) bagian belakang dan samping; (2) daerah tungkai bawah bagian belakang; (3) daerah tumit dan tapak kaki; (4) daerah tengkuk dan bahu memilik pengaruh yang besar terhadap penurunan perasaan lelah pasca latihan pada mahasiswa Pencak Silat Tapak Suci di UMKT. Dengan pemberian teknik efflurage yang baik kepada mahasiswa, maka hasil penurunan perasaan lelah dapat diturunkan secara signifikan.

Hasil penelitian ini serupa dengan penelitian sebelumnya yang dilakukan oleh (Ananto, 2017) menunjukkan bahwa penggunaan teknik efflurage pada subjek yang dilakukan dengan baik dan benar dapat menurunkan tekanan darah pada penderita hipertensi. Hasil analisis data diketahui bahwa teknik efflurage berpengaruh signifikan terhadap penurunan tekanan darah pada pasien atau penderita hipertensi. Data menunjukkan hasil uji t dengan nilai signifikan sebesar 0,000 atau hasil ini menunjukkan nilai yang lebih kecil dari 0,05 yang artinya terdapat perbedaan yang signifikan pada perlakuan massage dengan teknik efflurage terhadap tekanan darah hipertensi.

Penelitian serupa terkait penggunaan teknik petrissage yang dilakukan oleh Sumiati et al. (2017). Pada subjek yang berjumlah 20 responden, menunjukkan sebagian besar responden mengalami dismenorea sedang (nyeri haid sedang) yaitu sebanyak 23 responden atau sebesar $76,7 \%$ dan 7 responden mengalami nyeri ringan yaitu sebesar $23,3 \%$ sebelum diberikan teknik massage petrissage. Selanjutnya terjadi penurunan nyeri haid ringan sebanyak 22 responden dengan persentase $73,3 \%$, nyeri haid sedang sebanyak 2 responden yaitu $6,7 \%$ dan tidak nyeri sebanyak 6 responden yaitu dengan persentase $20 \%$ setelah diberikan perlakukan teknik massage petrissage, sedangkan hasil analisis data 
dengan melakukan Uji t diperoleh taraf signifikan sebesar 0,000 atau $\mathrm{p}<0,05$. Artinya terdapat pengaruh yang bermakna antara tingkat nyeri sebelum dan sesudah diberikan perlakuan massage petrissage.

Hasil analisis data penelitian ini didukung pula hasil penelitian yang dilakukan oleh Hatta dan Widodo (2019) tentang penggunaan massage pada penurunan asam laktat yang dilakukan. Sampel yang digunakan dalam penelitian adalah sebanyak 20 orang. Hasil analisis data yang diperoleh rata-rata pretest sebesar $12,85 \mathrm{mM} / 1$ dan post-test sebesar $8,08 \mathrm{mM} / \mathrm{l}$. Berdasarkan hasil uji normalitas data pre-test diperoleh $\mathrm{x}_{\text {tabel }}^{2}$ lebih besar dari pada $\mathrm{x}^{2}$ hitung yaitu 2,258 > 3,841 dan post-test sebesar 1,954>3,841 dengan hasil analisis tersebut data dikatakan berdistribusi normal. Pada uji perbedaan diketahui bahwa $\mathrm{t}_{\text {hitung }}$ sebesar 14,17 dengan taraf signifikan 0,05 dengan $\mathrm{df}=9$ adalah 1,833. $\mathrm{t}_{\text {hitung }}$ lebih besar dari pada $\mathrm{t}_{\text {tabel }}$ maka Ho ditolak dan Ha diterima yang berarti bahwa pengaruh massage efektif terhadap menurunkan asam laktat dalam darah setelah latihan anaerobik. Hasil data dapat disimpulkan bahwa massage berpengaruh signifikan terhadap penurunan kadar asam laktat dalam darah setelah melakukan latihan anaerobik dengan persentase penurunan sebesar $25,3 \%$.

Kemudian untuk menyatakan besar pengaruh teknik efflurage dan teknik petrissage terhadap penurunan perasaan lelah pasca latihan pada mahasiswa UKM Pencak Silat Tapak Suci UMKT, maka ditentukan dengan koefesien determinasi sebagai berikut: $\mathrm{K} \mathrm{KD}=\mathrm{R} 2 \times 100 \%$ dimana $\mathrm{KD}=99,8 \%$. Hasil data ini membuktikan bahwa pengaruh teknik efflurage $\left(\mathrm{X}_{1}\right)$ dan teknik petrissage $\left(\mathrm{X}_{2}\right)$ terhadap penurunan perasaan lelah (Y) pasca latihan pada UKM Pencak Silat Tapak Suci UMKT sebesar 99,8\% dan sisanya $0,2 \%$ dipengaruhi oleh faktor lainnya yang tidak diteliti. Hal ini menunjukkan bahwa pengaruh teknik efflurage dan teknik petrissage terhadap penurunan perasaan lelah pasca latihan pada mahasiswa UKM Pencak Silat Tapak Suci UMKT Tahun 2019 yang nilainya hampir 100\%.

\section{SIMPULAN}

Berdasarkan hasil analisis data, maka dapat disimpulkan bahwa: (1) Ada pengaruh yang signifikan antara pengaruh teknik efflurage dan teknik petrissage terhadap penurunan perasaan lelah pasca latihan pada mahasiswa UKM Pencak Silat Tapak Suci di UMKT; (2) Ada pengaruh yang signifikan antara pengaruh teknik efflurage dan teknik petrissage terhadap penurunan perasaan lelah pasca latihan pada mahasiswa UKM Pencak Silat Tapak Suci di UMKT; dan (3) Ada pengaruh yang signifikan antara pengaruh teknik efflurage dan teknik petrissage secara bersama-sama terhadap penurunan perasaan lelah pasca latihan pada mahasiswa UKM Pencak Silat Tapak Suci di UMKT.

\section{DAFTAR PUSTAKA}

Ananto, D. P. (2017). Pengaruh massage teknik effleurage terhadap tekanan darah pada penderita hipertensi di Desa Kalirejo Kabupaten Purworejo. Ilmu Keolahragaan, 1(1), 1-6. http://journal.student.uny.ac.id/ojs/ojs/index.php/ikora/article/viewFile/7521/7156

Arikunto, S. (2010). Prosedur penelitian: Suatu pendekatan praktik. Rineka Cipta.

Arovah, N. Intan. (2010). Masase dan prestasi atlet. Jorpres (Jurnal Olahraga Prestasi), 6(2), 116-122. https://doi.org/10.21831/jorpres.v6i2.10338

Best, T. M., Hunter, R., Wilcox, A., \& Haq, F. (2008). Effectiveness of sports massage for recovery of skeletal muscle from strenuous exercise. Clinical Journal of Sport Medicine: Official Journal of the Canadian Academy of Sport Medicine, 18(5), 446-460. https://doi.org/10.1097/JSM.0b013e31818837a1

Bompa, T. O., \& Haff, G. (2009). Periodization: Theory and methodology of training. Human Kinetics.

Callaghan, M. J. (1993). The role of massage in the management of the athlete: a review. British Journal of Sports Medicine, 27(1), 28-33. https://doi.org/10.1136/bjsm.27.1.28

Ekowati, R., Wahjuni, E. S., \& Alifa, A. (2012). Efek teknik masase effleurage pada abdomen terhadap penurunan intensitas nyeri pada disminore primer mahasiswi PSIK FKUB Malang. Politeknik Kesehatan Kementrian Kesehatan Malang.

Giriwijoyo, S., \& Sidik, D. Z. (2012). Ilmu faal olahraga (fisiologi olahraga). Remaja Rosdakarya.

Goats, G. C. (1994). Massage--the scientific basis of an ancient art: Part 1. The techniques. British Journal of Sports Medicine, 28(3), 149-152. https://doi.org/10.1136/bjsm.28.3.149

Graha, A. S., \& Priyonoadi, B. (2009). Terapi masase frirage penatalaksanaan cedera pada anggota 
tubuh bagian atas. Universitas Negeri Yogyakarta.

Hadi, S. (1991). Analisis butir untuk instrumen. Andi Offset.

Handayani, R., Winarni, W., \& Sadiyanto, S. (2013). Pengaruh massage effleurage terhadap pengurangan intensitas nyeri persalinan kala i fase aktif pada primipara di RSIA Bunda Arif Purwokerto tahun 2011. Jurnal Kebidanan, 5(2). https://doi.org/10.35872/jurkeb.v5i2.114

Hatta, H. W. S., \& Widodo, A. (2019). Pengaruh masase terhadap penurunan asam laktat setelah melakukan latihan kekuatan (Studi pada siswa kelas XII SMA Negeri Kota 1 Mojokerto). Jurnal Kesehatan Olahraga, 8(1). https://jurnalmahasiswa.unesa.ac.id/index.php/jurnal-kesehatanolahraga/article/view/30610

Kusumawardhana, B. (2016). Menurunkan kadar glukosa darah penderita diabetes melitus tipe-2 melalui latihan aerobic low impact dan ritmis. Jendela Olahraga, 1 (1 Juli).

Kuswanto, C. W. (2016). Penyusunan tes fisik atlet pencak silat dewasa kategori tanding. Jurnal Keolahragaan, 4(2), 145. https://doi.org/10.21831/jk.v4i2.6423

Lubis, J. (2004). Pencak silat: Panduan praktis. RajaGrafindo Persada.

Priyonoadi, B. (2008). Sport massage. Fakultas Ilmu Keolahragaan, Universitas Negeri Yogyakarta.

Purnama, R. D., \& Graha, A. S. (2019). Efektifitas masase dan terapi latihan fleksibilitas terhadap pemulihan rasa nyeri dan kelentukan extremitas bawah pada kiper. Massage for Sport Therapy and Injury, 1(1), 1-6. https://doi.org/10.33292/mastri.v1i1.4

Purnomo, M. (2011). Asam laktat dan aktivitas sod eritrosit pada fase pemulihan setelah latihan submaksimal. Media Ilmu Keolahragaan Indonesia, $1(2)$. https://doi.org/10.15294/miki.v1i2.2031

Purwanti, S. (2013). Analisis perbedaan terapi dismenorhea dengan metode effleruage, kneading, dan yoga dalam mengatasi dismenorhea. Jurnal Kebidanan, 5(01), 10. https://doi.org/10.35872/jurkeb.v5i2.106

Robertson, A., Watt, J. M., \& Galloway, S. D. R. (2004). Effects of leg massage on recovery from high intensity cycling exercise. British Journal of Sports Medicine, 38(2), 173-176. https://doi.org/10.1136/bjsm.2002.003186

Saputro, G. E., Hanief, Y. N., Herpandika, R. P., \& Saputro, D. P. (2018). Modul tutorial sebagai media pembelajaran pencak silat untuk siswa sekolah menengah kejuruan. Jurnal Keolahragaan, 6(2), 130-138. https://doi.org/10.21831/jk.v0i0.21099

Sherwood, L. (2015). Fisiologi manusia: Dari sel ke sistem (D. R. Herman Octavius Ong, Albertus Agung Mahode (ed.); 8th ed.). EGC.

Smith, L. L., Fulmer, M. G., Holbert, D., McCammon, M. R., Houmard, J. A., Frazer, D. D., Nsien, E., \& Israel, R. G. (1994). The impact of a repeated bout of eccentric exercise on muscular strength, muscle soreness and creatine kinase. British Journal of Sports Medicine, 28(4), 267-271. https://doi.org/10.1136/bjsm.28.4.267

Sugiyono. (2010). Metode penelitian kuantitatif kualitatif dan $R \& D$. Alfabeta.

Sukadiyanto, S., \& Muluk, D. (2011). Pengantar teori dan metodologi melatih fisik. Lubuk Agung.

Sumiati, E., Sepriana, C., Agatha, M. Y., \& Oktviani, D. (2017). Pengaruh pemberian massage petrissage terhadap penurunan dismenorea pada siswi MAN 2 Sumbawa Besar. PrimA: Jurnal Ilmiah Ilmu Kesehatan, 3(1), 80-86. http://128.199.127.86/ejournal/index.php/JPRI/article/view/67

Yudiansyah, Y. (2015). Perbedaan pengaruh latihan fisik aerobik dengan latihan fisik anaerobik terhadap aktivitas creatine kinase (CK) pada otot jantung tikus (rattus norvegicus) galur wistar. Masker Medika, 3(1), 53-63. http://ejournal.stikesmp.ac.id/index.php/maskermedika/article/view/213 